\title{
Do April showers bring May flowers? Knowledge and perceptions of local biodiversity influencing understanding of global environmental change. A presentation of the PIAF project
}

\author{
Anne Sourdril ${ }^{1, *}$, Meredith Welch-Devine ${ }^{2}$, Émilie Andrieu ${ }^{3}$ and Nadia Bélaïdi ${ }^{4}$ \\ 1 Anthropology, CNRS, UMR7533 Ladyss, Nanterre, France \\ 2 Anthropology, Interdisciplinary Graduate Studies, University of Georgia, Graduate School, Athens, Georgia, USA \\ 3 Ecology, Inra, INPT-ENSAT, UMR1201 Dynafor, Castanet-Tolosan, France \\ 4 Anthropology of Law, CNRS, UMR7206 Éco-Anthropologie et Ethnobiologie, Paris, France
}

\begin{abstract}
The multidisciplinary and comparative PIAF program (ANR Jeunes Chercheurs 2014-2018) uses perceptions and discourse relating to biodiversity to investigate local understandings of environmental change and strategies for adaptation to those changes. Beginning from the hypothesis that a person's connection to the environment differs according to his or her degree of dependence on natural resources and place of residence, we examine perceptions and strategies on an urban-rural-protected area gradient in four northern and southern countries (France, the United States, Cameroon, and Zimbabwe). PIAF brings together social and natural scientists who seek to contribute to our understanding of perceptions and knowledge related to environmental change and, more globally, to our understanding of social-ecological interactions in a situation of change, social and environmental tensions, and dynamics of socio-ecological systems.
\end{abstract}

Keywords: environment / biodiversity and natural resources / environmental changes / indicators / comparative and interdisciplinary approaches

\begin{abstract}
Résumé - Les hirondelles ne font-elles plus le printemps ? Le projet PIAF ou comment saisir les perceptions et savoirs autour de la biodiversité pour comprendre l'appréhension locale des changements environnementaux globaux. Le programme pluridisciplinaire PIAF (ANR Jeunes Chercheurs 2014-2018) cherche à saisir les perceptions et stratégies locales d'adaptation aux changements environnementaux à partir des discours sur la biodiversité ordinaire, cela dans une perspective comparative. Partant de l'hypothèse que la connexion à l'environnement est différente suivant le degré de dépendance des populations aux ressources naturelles et suivant les lieux et contextes de résidence, nous interrogeons ces perceptions et stratégies sur un gradient ville - campagne - zone protégée dans quatre pays de l'hémisphère Nord et de l'hémisphère Sud (France, États-Unis, Cameroun, Zimbabwe). PIAF regroupe un collectif de (jeunes) chercheurs en sciences humaines et sociales et en sciences biologiques cherchant à contribuer à la compréhension de la perception et des savoirs sur les changements environnementaux et plus globalement à la compréhension des interactions sociétés/environnement en contexte de mutations, des tensions sociales et environnementales associées à ces changements et des dynamiques des systèmes socioécologiques.
\end{abstract}

Mots-clés : environnement / biodiversité et ressources naturelles / changements environnementaux / indicateurs / approches comparative et interdisciplinaire

The need to document and understand the consequences of global change on the environment and society has led to the development of scientific indicators

\footnotetext{
* Corresponding author: asourdril@u-paris10.fr
}

of change or adaptation (Niemi and McDonald, 2004). Though these scientifically-derived indicators and environmental changes are at the heart of numerous research programs in both the social and natural sciences, local concerns relating to causes or consequences of 
environmental change have been understudied (Veteto and Carlson, 2014). It is precisely these local, ad hoc, and iterative efforts based on non-scientific knowledge derived from direct observation and lived experience, though, that will be critically important in adaptation to environmental change (Roncoli et al., 2001).

In the context of the PIAF program ${ }^{1}$, we seek to document local perceptions of global environmental change as understood through observations of biodiversity and to identify the conscious or unconscious strategies used to adapt to these changes. Advancing our theoretical and empirical understanding of local adaptation strategies is a necessary complement to formal scientific knowledge and can improve our understanding of change, of the state of biodiversity, and of local management (Fiske et al., 2014). It requires long-term multidisciplinary research linking social and natural sciences and focusing on interactions of individuals and groups with their environment (Crate and Nutall, 2009). PIAF brings together researchers from the social sciences (anthropology, geography, and law) and the natural sciences (landscape ecology, and forestry) and is comparative across four countries (France, the United States, Cameroon, and Zimbabwe). Through our site comparisons, we seek to arrive at a general description of local understandings of environmental change in both the global North and South and to understand how different societies address these changes.

This article describes the PIAF program at its inception, and engages in a reflexive return to our comparative and interdisciplinary objectives two years after the beginning of the research. We first discuss our approach to investigating questions of environmental change, indicators, and local knowledge and how we link them. We then show how we designed our comparative methods, what we expected the interdisciplinary nature

\footnotetext{
${ }^{1}$ PIAF (Programme Interdisciplinaire sur les Indicateurs Autochtones de la Flore et de la faune) is a project funded by the ANR Young Researcher Program ANR-13-JSH1-0005 from 2014 to 2018: http://www.anr-piaf.org. PIAF brings together a research team from 6 research institutes and 10 research laboratories and is coordinated by Anne Sourdril (CNRS, UMR7533 Ladyss). The team is composed of (by laboratory and alphabetical order): A. Sourdril; Émilie Andrieu, Cécile Barnaud, Marc Deconchat, Wilfried Heinz, Sylvie Ladet (Inra UMR1201 Dynafor); Nadia Bélaïdi (MNHN UMR7206 Écoanthropologie et Ethnobiologie); Éric Garine, Émilie Guitard, Jean Wencélius (Université Paris Nanterre, UMR7206 LESC); Christine Raimond (CNRS, UMR8586 Prodig); Michel de Garine-Wichatitsky (Cirad); Sylvain Aoudou Doua (Université de N'Gaoundéré, Cameroon); Brian J. Burke (Appalachian State University, USA); Ted Gragson, Meredith L. WelchDevine (University of Georgia, USA), Hervé Fritz, Chloé Guerbois (CNRS, UMR5558 LBBE).
}

of the project to add to our analysis of perceptions of change and how we approach comparison and interdisciplinarity.

\section{Global diagnostics vs. local diagnostics: the question of local perceptions of environmental change}

PIAF, though interdisciplinary, is principally anchored in social anthropology, ethnoscience, and human ecology, examining the role of knowledge and indicators of local change in the understanding of global environmental change. PIAF is based on one primary research question: how do local populations develop diagnostics of environmental change, and how do different forms of knowledge (lay, scientific) and discourse (local, global) compete and interact to help shape the knowledge and skills that local actors develop to cope with the changes they are experiencing? We select the changes to study as they emerge from popular discourse, rather than studying changes selected a priori (e.g. climate change or land conversion). We seek to identify potential differences and disconnects between changes identified at different scales, the factors identified as driving them, and the consequences and responses to them. In doing so, we focus on how local discourses on biodiversity provide crucial insights about perception and adaptation to those changes. PIAF is organized around four central hypotheses: 1) People's perceptions of change and the causes of that change can be elucidated by analyzing discourse and local knowledge of biodiversity and natural resource use. The status of biodiversity, in terms of species richness or abundance and changes therein, can then serve as a local indicator of environmental change, and its observations can assist in the formulation of adaptation strategies for individuals using their immediate environments. 2) Indicators and changes perceived by local actors can vary according to personal attributes (e.g. age, gender), geographic locations, the connection - through socio-economic factors, policies or media representation - that individuals and groups have with their environment or their biodiversity, and according to their degree of dependence on natural resources. 3) Local diagnostics will allow local groups to manage or protect their local environments and the biodiversity therein but will also create or reveal power relations associated with the development of resultant adaptation strategies. 4) In the different studied populations there will be variability in knowledge but also similarities in the ways in which people observe change and in which species are privileged as indicators, particularly when they are ritual or sacred species, resource species (game animals, edible plants, forage), or species that display a predictable behavior from one year to the next, such as migratory species. To achieve our 


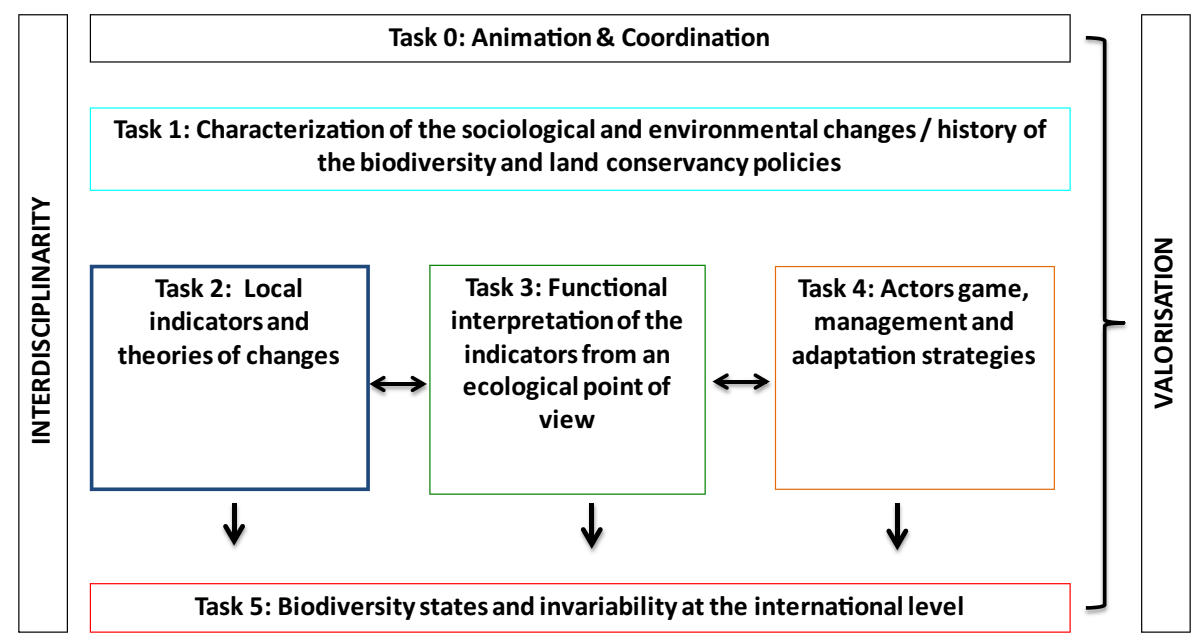

Fig. 1. Tasks in PIAF.

goals and test our hypotheses, we divided the PIAF project in five main tasks (Fig. 1): Task 1 should provide us, based on existing knowledge and data, with a preliminary global grid of the past and current social and environmental changes in each of our fieldsites and of the land uses, conflicts or policies among the studied areas. Tasks 2 and 3 are the heart of our project and will provide us with (1) a precise description of the local diagnostics of environmental changes and state of biodiversity at each site level based on ethnographic inquiries and (2) a scientific description of the biodiversity changes and ecosystem services based on the species and indicators identified by local informants. Task 4 will allow us to understand the actor relationships linked with land uses and biodiversity conservation questions - conflicts, tensions, cooperation, interactions, etc. - and should give us insights into the adaptation strategies put into practice. Task 4 should also give us the opportunity to understand discrepancies that could be identified by the juxtaposition of Tasks 2 and 3. Task 5 should generate, through comparative analysis of the diagnostics, differences and similarities among the perceptions and knowledge of the local informants in the different hemispheres, countries and regions of our projects. This task should result in the building of a list of common categories and of methodological recommendations to understand local perceptions of changes for international conservation groups such as IPBES (Intergovernmental Science-Policy Platform on Biodiversity and Ecosystem Services).

\section{Study sites: understanding perceptions of change in France, the United States, Cameroon, and Zimbabwe}

The effects of environmental change vary from region to region, requiring a multi-sited, comparative approach (Crate and Nutall, 2009). PIAF was designed to undertake comparisons at multiple scales: at the international level (between the different countries in which our field sites are located), and at the local and regional scales (across our types of subsites). It seeks to understand the (in)variability of perceptions of environmental change in southwestern France, in the Haute Bénoué region of northern Cameroon, in the southern Appalachian mountains of the United States, and in the Hwange region of Zimbabwe (Fig. 2). In each country, a gradient of three sites - urban/peri-urban, rural (comprised primarily of private lands), and protected areas - was chosen to test our second hypothesis, concerning the influence of the connection to the environment and the degree of dependence on natural resources on diagnostics of change. Though differing in their biogeography, socio-economic, and political contexts, each site is facing similar changes: global environmental change, demographic pressures (rapid growth and urbanization, as well as influx of outsiders who bring with them changes in values and orientation to the land) and environmental protection efforts (creation of protected areas, growing body of regulations, global environmental policy, or biodiversity conservation policies that disrupt local usages and control over land). Each of our study sites forms part of either a Zone Atelier or Long Term Ecological Research Network $\left(\right.$ LTER $\left.^{2}\right)$. These long-term research programs and data sets were incorporated to give PIAF an excellent foundation for understanding the social and environmental dynamics of these sites as well as to facilitate access to the field sites and to benefit from former local collaborations. This approach, while

\footnotetext{
${ }^{2}$ See here for more information about the Zone Ateliers' aims and objectives: http://www.za-inee.org/fr/ateliers and see here for more information concerning the LTER site: https://www. lternet.edu.
} 


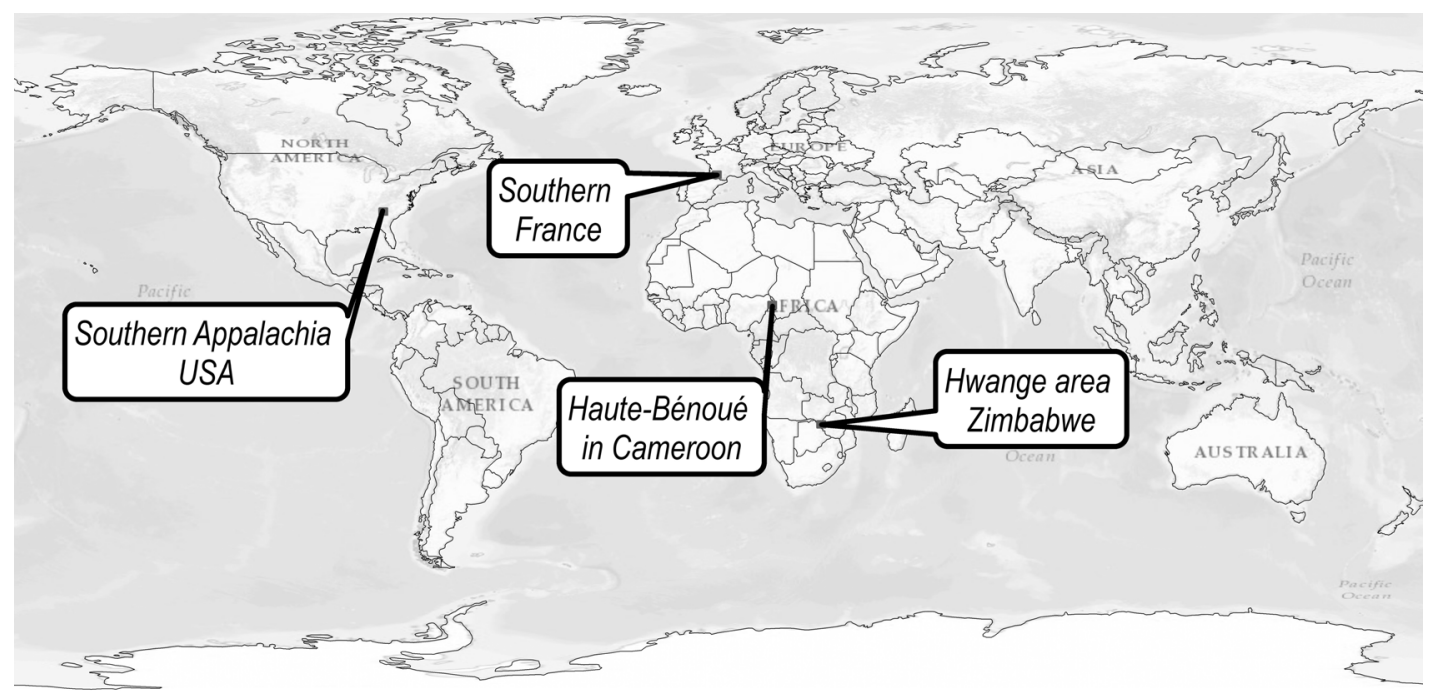

Fig. 2. Map of the study areas of the PIAF program.

providing significant advantages, was not without challenges, which are detailed below.

\section{Reevaluating our objectives after the completion of the first field studies: comparison and interdisciplinarity, a matter of data?}

As of spring 2016, we are 2 years into the PIAF project and have completed one full year of field studies. Two workshops of 3 days each, one in September 2014 and one in December 2015, 5 one-day conferences every six months, and multiple year-round meetings, which brought most of the participants together, have enabled us to use an iterative and reflexive approach to the building and design of our research program and to continue to refine our comparative and interdisciplinary objectives.

In order to facilitate comparison across our sites, we decided at the beginning of the project that building a common methodology would be critical. We chose to base our interdisciplinary and comparative approaches on similar data to be collected at the sites and to be analyzed by the scientists involved in the program. A common methodology has been developed at three levels that correspond to three phases of the research program: exchange, data collection, and comparison.

\section{Phase 1: exchange}

This phase was characterized by an attempt to assess and standardize the scientific knowledge already available for each of the field sites (approaches, data, results). Using our detailed knowledge of the field sites, published data, and unpublished data sets, we drafted synthetic descriptions of each site and created comparative tables displaying relevant information for each site (Task 0, 1 and 3), trying to get a description of all sites with the objective of choosing some relevant criteria of comparison (Vigour, 2005). Questions about the actual comparability of the sites and data were first raised during the building of a comparative preliminary grid. We produced a shared table with 17 entries - from physical environment to biodiversity, land-uses, demography or conflicts - that gives us the necessary information to characterize and compare the different field sites. Developing the table was, however, a challenge and made us re-think the availability, match and re-use of the existing data for our project. Working with programs such as LTER we had ample available data about the study but faced challenges in accessing data and parsing them to make them comparable at useful scales.

\section{Phase 2: data collection}

The objective of this phase was to collect new data through the use of a common protocol to assure data comparability. Our research protocol includes provisions for multiple researchers and technicians in and across field sites. As a result, we drafted a methodological manual - a shared handbook based on a common sampling strategy and similar interview guidelines, commented transects and freelist elicitation methods formalizing both data collection (samplings or strict guidelines) and data management (timelines, table to be filed). These data are to be integrated into a common database where, without attempting a complete standardization of the data, we will place them in similar form across the different sites (Tasks 0, 2, 3 and 4). The protocol was built by a small working group of PIAF researchers consisting of one political ecologist, one social geographer and two cultural anthropologists, and 
then shared and validated with all participants during dedicated meetings. Natural scientists did not take part directly in the building of the protocol itself as field investigations, in the ecological domains had not been planned. As the protocol was being built, questions were raised by the different types of researchers involved: researchers from the social sciences were worried by the constraints of following such prescriptive guidelines, which could make it difficult to capture and represent the fine grain of the observed phenomena. Some researchers from the natural sciences, on the contrary, were worried by a protocol that they found less structured than they were accustomed to and by the possibility that using multiple fieldworkers would result in non-comparable data (fieldworker effect). Those questions were resolved during the first field work season, during which we were able to demonstrate that the protocol could be successfully adapted to each site; the fieldworker effect was minimized through training and the understanding that the focus was on obtaining the necessary data rather than adhering strictly to the guidelines themselves. Fieldwork was conducted in all 12 sites between February 2015 and June 2016. The PIAF field team is composed of 14 interns - mainly sociologists, geographers and anthropologists - and 8 project investigators - permanent and postdoctoral researchers. The PIAF dataset is now filled with more than 450 transcribed semi-structured interviews, 420 informant files, 250 Excel documents with freelist information on birds, trees, mammals and plants - which translates to more than 900 individual freelists; we also have hundreds of participant observation descriptions, and thousands of pictures to be further analyzed and compared.

\section{Phase 3: comparison}

In this phase - in progress - we plan to use a common analysis protocol to construct a comparative analysis of both quantitative and qualitative data, to highlight the viewpoints of different actors and groups studied, and to compare the lay and scientific perceptions of changes and indicators (Task 0 and 5). We shall return to this point at the close of our paper.

Data availability and consistency are one of the key aspects of our interdisciplinary and comparative reflections, and have been a challenge from the beginning of the project for all the disciplines involved in PIAF. The main area of collaboration between the social and natural sciences in our project is in the field of indicators of change. At the beginning of the project we hypothesized that we could empirically demonstrate the occurrence or nonoccurrence of the changes of interest to us, and that the indicators named by our study populations could be empirically demonstrated to be connected, or not, to those changes. PIAF aims to identify beliefs about relationships between indicators and change that may not be validated by scientific studies but that nevertheless inform adaptation strategies that are in use. Methodologically, we wanted to approach our interdisciplinary collaboration by comparing the indicators and changes identified by local participants with those identified in the scientific literature or in previous site studies on species abundance and richness.

After further investigation into the available data, through the grid built during Phase 1, the potential contributions of incorporating these previous studies into PIAF became less clear. The appropriate data can be, quite simply, difficult to identify, find, and access and they can be collected and formalized in ways that make them difficult to integrate and compare (Grimm et al., 2000; Parsons et al., 2011; Sievanen et al., 2012). Additionally we found it difficult to identify datasets that matched well with the concerns of our informants. We hypothesized at the beginning of the project that the indicators and diagnostics of change that would arise from ethnographic inquiries would parallel the observations of ecologists and that they could be compared. But this is not always the case. In rural and protected areas in France for example, we thought - at the beginning of the project and according to the existing data - that changes of seasonality and of climate would be of great importance to local actors and that birds would be relevant indicators of such changes. We hypothesized that bird observations were crucial for local farmers to adapt their agricultural practices. Fieldwork showed, however, that when people talked about changes in climate and birds, they were not directly linking them together and that their diagnoses could even be opposite to those of the ecologists. Local people report seeing and hearing more birds now than previously, while ecologists have noted a decrease in bird populations and species diversity. The difference may rest on the species of birds observed or the types of habitats on which people base their observations. We will use anthropological inquiries in late 2016 and 2017 to further address these issues. Unexpectedly, we also found that the main local concerns were focused on social changes and that the most relevant indicators of environmental and social changes were based on species considered as pest species (e.g. weeds, ticks, wild boars). There is comparatively little ecological data available on these types of species. These new observations on pests opened a new range of potential research projects to be conducted by ecologists in collaboration with social scientists in the near future.

The early phases of the project focused on questions of interdisciplinarity, and the role of the natural scientists in PIAF. After the first year of fieldwork, 
we had to re-design the participation of ecologists in the collaborative work. Because both social and natural scientists were brought into the research program at the same time and all helped design the research questions and methodology, this challenge was embraced collectively and we succeeded in making fundamental new contributions to the direction of the research. During the last PIAF atelier in December 2015 we primarily discussed the data collected during the first fieldwork phase and on how to analyze these data and put into practice the comparison and the interdisciplinary work. We discussed the limitations of our first interdisciplinary objectives, the available useful ecological data and the way social scientists and ecologists could both participate in the analysis of some sociological data. This led to new interdisciplinary challenges within our program and new roles for the ecologists. Within the PIAF program there is no direct investigation of issues based on ecological methodologies, so we chose to see how ecology and ecologists could help in the analysis of ethnographic data from an interdisciplinary point of view. PIAF ecologists will use their analytical tools and knowledge to provide quantitative analyses of the ethnographic data collected, notably within the freelists. The objectives are not to answer questions about the effects of climate change on species, for example, but to find equivalences among relevant species/indicators between countries for local actors: do these indicators have similar characteristics, common patterns to be tested at other study sites of the program - providing at the same time new possibilities for comparison at our gradient and international scales. The collaboration between social and ecological sciences in PIAF, goes then simply beyond providing one-way validation or invalidation by formal scientific inquiry of local perceptions of indicators and changes.

The PIAF researchers have experience in long-term, collaborative interdisciplinary scholarship (see for example: Gragson and Grove, 2006; Deconchat et al., 2007; Guerbois et al., 2012; Sourdril et al., 2012), and several among us have collaborated earlier. We do have an understanding of what is required for success in interdisciplinary projects, as well as what typically heralds failure. Though PIAF initially faced challenges of interdisciplinarity, data, and the role of ecologists, we are now attempting to link and crossreference data and are comparing our understandings of each site to build a common view of the studied situations (Mathieu et al., 1997; Riaux, 2013) in order to further reciprocal understanding (Billaud, 2003). This was made possible by the regular interactions between our team members who are familiar with the concepts, methods, and approaches of the other disciplines. We have reflected in depth on how to develop and maintain a constructive dialogue between our disciplines and share a holistic approach to our sites and research objectives, which facilitates mutual understanding and our ongoing comparisons (Jollivet, 1992; Jollivet and Legay, 2005; Riaux, 2013).

\section{Societal perspectives: analyzing local knowledge through the lenses of socio-ecological systems and environmental justice}

The PIAF project contributes to a broader project of understanding and describing society-environment interactions; in doing so, it will shed light on the analysis of two scientific concepts designed to explain this type of interaction: socio-ecological systems and environmental justice. The concept of socio-ecological systems is typically used to highlight the artificiality and arbitrariness of the distinction between social and ecological systems and to show their dynamic and interdependent natures (e.g. Berkes et al., 2001; Anderies et al., 2004; Folke, 2006). The local indicators of change we are studying provide information on the dynamics of our research sites that some of our teams explicitly describe as social-ecological systems (Hwange National Park or the Bas-Comminges, rural area of the southwestern France studied). Our comparative approach will allow us to revisit these concepts and to show how our fieldsites can be considered as socio-ecosystems and why. Thus, from the way the different disciplines approach this notion, we can determine the limits and contributions of this concept to characterize the situations we observe.

The reference to society-environment interactions, which is inherent to the concept of socio-ecosystems, offers us the opportunity to question the social implications of this relationship and leads us to mobilize the concept of environmental justice. The latter concerns justice between social groups within a given environment and justice for ecosystems (or socio-ecosystems). Through PIAF, we seek to identify the requirements presented by different types of local actors to achieve environmental justice, that is to say, maintaining a "safe" and "healthy" environment, an equitable access to natural resources and a recognition of the roles and knowledge of the actors in their territories. The question of access to power and representation is also brought into the discussion. The discovery of these conditions can reveal conflicts or forms of consensus that the use of the concept of environmental justice, used as a "reading grid of the social phenomenon" could highlighten; this by questioning different "social values" attached by the populations to their relations with their environment (Bélaïdi, 2015). Here we find all the elements of environmental justice: environmental justice in maintaining a healthy environment and social 
environmental justice for redistribution and recognition. These sets of values could be compared for each fieldsite with institutional and cultural frameworks, at various local, regional or national scale (e.g. the Treaty of KAZA TFCA for Zimbabwe, the environment Charter in France). This could help us understand more broadly societyenvironment interactions and dynamics as experienced and envisaged by the populations and/or staged by the institutions. The use of the concept of environmental justice contributes to the overarching objective of PIAF, which is the understanding of the variability of perceptions and knowledge about environmental change and the comparison of local and global discourse on these changes and urgency associated therewith.

\section{References}

Anderies J.M., Janssen M.A., Ostrom E., 2004. A framework to analyze the robustness of social-ecological systems from an institutional perspective, Ecology and Society, 9, 1, 18, www.ecologyandsociety.org/vol9/iss1/art18/.

Bélaïdi N., 2015. Théorie du droit et front écologique : apport à la (re)définition de la justice environnementale, Développement durable et territoires, 6,1 , http://developpement durable.revues.org/10806, doi:10.4000/developpementdur able.10806.

Berkes F., Colding J., Folke C., 2001. Linking social-ecological systems, Cambridge, Cambridge University Press.

Billaud J.-P., 2003. De l'objet de l'interdisciplinarité à l'interdisciplinarité autour des objets, Natures Sciences Sociétés, 11, 1, 29-36.

Crate S.A., Nutall M., 2009. Anthropology and climate change: from encounters to actions, Walnut Creek (CA), Left Coast Press.

Deconchat M., Gibon A., Cabanettes A., Du Bus De Warnaffe G., Hewison M., Garine E., Gavaland A., Lacombe J.-P., Ladet S., Monteil C., Ouin A., Sarthou J.-P., Sourdril A., Balent G., 2007. How to set up a research framework to analyze social and ecological interactive processes in a rural landscape, Ecology and Society, 12, 1, 15, www.ecolo gyandsociety.org/vol12/iss1/art15/.

Fiske S.J., Crate S.A., Crumley C.L., Galvin K., Lazrus H., Lucero L. Oliver-Smith A., Orlove B., Strauss S., Wilk R., 2014. Changing the atmosphere. Anthropology and climate change. Final report of the AAA Global Climate Change Task Force, Arlington, American Anthropological Association.

Folke C., 2006. Resilience: the emergence of a perspective for social-ecological systems analysis, Global Environmental Change, 16, 253-267.
Gragson T.L., Grove M., 2006. Social science in the context of the long term ecological research program, Society and Natural Resources, 19, 93-100.

Grimm N., Grove J., Pickett S., Redman C., 2000. Urban ecological systems present multiple challenges to ecologists pervasive human impact and extreme heterogeneity of cities, and the need to integrate social and ecological approaches, concepts, and theory, BioScience, 50, 7, 571-584.

Guerbois C., Chapanda E., Fritz H., 2012. Combining multiscale socio-ecological approaches to understand the susceptibility of subsistence farmers to elephant crop raiding on the edge of a protected area, Journal of Applied Ecology, 49, 1149-1158.

Jollivet, M. (Ed.), 1992. Sciences de la nature, sciences de la société. Les passeurs de frontières, Paris, CNRS Éditions, http://books.openedition.org/editionscnrs/4154.

Jollivet M., Legay J.-M., 2005. Canevas pour une réflexion sur une interdisciplinarité entre sciences de la nature et sciences sociales, Natures Sciences Sociétés, 13, 2, 184188.

Mathieu N., Rivault C., Blanc N., Cloarec A., 1997. Le dialogue interdisciplinaire mis à l'épreuve: réflexions à partir d'une recherche sur les blattes urbaines, Natures Sciences Sociétés, 5, 1, 18-30.

Niemi G.J., McDonald M.E., 2004. Application of ecological indicators, Annual Review of Ecology, Evolution, and Systematics, 35, 89-111.

Parsons M., Godøy Ø., LeDrew E., de Bruin T., Danis B., Tomlinson S., Carlson D., 2011. A conceptual framework for managing very diverse data for complex, interdisciplinary science, Journal of Information Science, 37, 6, 555-569.

Riaux J., 2013. Engager la construction d'un regard sociohydrologique: des archives catalyseurs de l'interdisciplinarité, Natures Sciences Sociétés, 21, 1, 15-23.

Roncoli K.T., Ingram K., Kirshen P., 2001. The cost and risk with copying the drought. Livelihood impact and farmers' responses in Burkina Faso, Climate research, 19, 2, 119-132.

Sievanen L., Campbell L., Leslie H., 2012. Challenges to interdisciplinary research in ecosystem-based management, Conservation Biology, 26, 2, 315-323.

Sourdril A., Andrieu E., Cabanettes A., Elyakime B., Ladet S., 2012. How to maintain domesticity of usages in small rural forests? Lessons from forest management continuity through a French case study, Ecology and Society, 17, 2, 6, www.ecologyandsociety.org/vol17/iss2/art6/.

Veteto J., Carlson S., 2014. Climate change and apple diversity: local perception from Appalachian North Carolina, Journal of Ethnobiology, 34, 3, 359-382, doi:10.2993/0278-077134.3.359.

Vigour C., 2005. La comparaison dans les sciences sociales, Paris, La Découverte.

Cite this article as: Sourdril A., Welch-Devine M., Andrieu É., Bélaïdi N., 2017. Do April showers bring May flowers? Knowledge and perceptions of local biodiversity influencing understanding of global environmental change. A presentation of the PIAF project. Nat. Sci. Soc. 25, 1, 56-62. 